\title{
Decreased sensitivity to punishment ${ }^{1}$
}

\section{LAWRENCE WEINSTEIN, ${ }^{2}$ University of Oklahoma, Norman, Okla. 74074}

Experience with a particular punishing stimulus rendered individuals less sensitive to a later presentation of this or a novel punishment. These findings agree with studies involving animal Ss.

Although it is typical for punishing stimuli to impair behavior, studies with animal Ss have found that this occasionally does not occur. Investigations involving animal Ss have found that exposure to a particular punishing stimulus renders an organism less sensitive to further presentations of this stimulus. Azrin (1960) reported that a brief shock immediately after each response substantially reduced behavior. On subsequent days, however, response rate was not affected by the shock. This decrease in sensitivity has been observed when using a bar-slap with rats (Skinner, 1938), noise with pigeons (Holz \& Azrin, 1962), and shock with monkeys (Hake \& Azrin, 1963). Little information is available concerning how human Ss respond to continued exposure to the same punishing stimulus.

Another instance where this class of stimuli fails to impair behavior involves a decrease in sensitivity to a novel punishing stimulus. Studies with animal Ss have found that exposure to a particular punishing stimulus renders an animal less sensitive to a novel punishing situation. Terris \& Wechkin (1967) have shown that rats who experienced mild shock followed by an airblast showed less behavior impairment during the airblast than animals who were exposed to the airblast subsequent to the shock. Little is known concerning how human Ss respond to a punishing situation different from the initial one.

Since information is minimal concerning the sequential effects of punishment on human Ss, an experiment was designed to investigate this issue.

Initially, in a pilot study, it was found that either people shaking their heads with disapproval or a 3-sec flickering light which indicated an imminent annoying shock is a punishing stimulus to human Ss working mental multiplication problems. An experimental group worked problems without pencil and paper seated next to four confederates who worked the problems with pencil and paper and who shook their heads with disapproval immediately after the S's first answer to each problem. In one control group the confederates did not shake their heads and in the other control group no confederates were present. The experimental group took significantly longer to answer than either control group. Another experimental group was informed that anywhere in the session a flickering light might come on during which an annoying shock was likely to occur. This group received a $3-\mathrm{sec}$ light immediately after the first answer to each problem. One control group was given the same information but received no light and another control group received no information and no light. The experimental group took significantly longer to answer than either control group.

The first prediction involves individuals who experience the same punishment (i.e., flickering light) twice. During the second experience these individuals should perform better than Ss who experience this punishing stimulus subsequent to no punishment. The second prediction involves individuals who experience both punishing situations in succession (i.e., flickering light then shaking heads). During the second punishment (i.e., shaking heads) these Ss should perform better than Ss who experience this punishing situation subsequent to no punishment.

\section{SUBJECTS}

The Ss were 28 male and 32 female undergraduate students enrolled in an introductory psychology course at the University of Oklahoma.

\section{MATERIALS}

The materials consisted of a $35-\mathrm{mm}$ slide projector $5 \frac{1}{2} \mathrm{ft}$ from a 5 -in. square piece of cardboard which served as a screen, slides $2 \times 1 \frac{1}{2}$ in. with digits typed on them (i.e., $245 \times$ 6), an Esterline Angus Model A620X multiple events recorder, a Lafayette Model 5226 disconnected shock apparatus, and a critical flicker frequency device controlled by E.

\section{PROCEDURE}

Table 1 summarizes the experimental procedure.

During Phase 1 a set of six problems was worked. Five minutes later (Phase 2) a similar set of problems was attempted. One answer or $50 \mathrm{sec}$ (whichever came first) was allowed for each problem and there were $8 \mathrm{sec}$ between problems.

The problems were worked in three situations. Ss experienced a 3 -sec flickering light (FL) immediately after the first answer to each problem; during the light shock was likely to occur. In another situation Ss attempted the problems seated next to four confederates who shook their heads (SH) with disapproval immediately after the S's first answer to each problem and finally some individuals experienced no punishment (NP).

Subjects who received FL were read the following instructions:

"This is an experiment in abstract problem solving, the ability to rapidly work problems involving abstract reasoning. You will be given some problems to work. Each one consists of a three-digit number multiplied by a one-digit number. You are to mentally (without pencil and paper) multiply the numbers as quickly as you can and then tell me your answer.

"During this set of problems you will received a series of flickering lights; while the light flickers a painful but not harmful electric shock is likely to occur. These lights which indicate impending shock are programmed so that you will never know when they will occur. You may receive several in a row or they may be widely spaced. Remember that you should try to work as quickly as you can. Do you have any questions?"

In the instructions to the NP Ss reference to the flickering light was omitted.

Those Ss who received SH were read the following instructions:

"This is an experiment in abstract problem solving, the ability to rapidly work problems involving abstract reasoning. You will be given some problems to work. Each one consists of a three-digit number multiplied by a one-digit number. The people seated next to you will work the problems with pencil and paper. You are to mentally (without pencil and paper) multiply the numbers as quickly as you can and then tell me your answers. Do you have any questions?"

Table 1

Summary of Experimental Procedure

\begin{tabular}{cccccccc} 
& & \multicolumn{7}{c}{ Group } \\
& 1 & 2 & 3 & 4 & 5 & 6 \\
\hline \multirow{2}{*}{ Phase } & 1 & NP & NP & FL & SH & FL & SH \\
& 2 & FL & SH & FL & SH & SH & FL \\
\hline
\end{tabular}


Table 3

Distribution of "Same" Responses

$\begin{array}{llllllllllllll}\text { Frequency } & 1 & 2 & 8 & 40 & 25 & 58 & 57 & 30 & 18 & 12 & 13 & 5 & 1\end{array}$

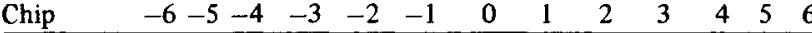

Each point in the table was calculated from the average of 24 trials. A difference limen is indicated for each of the six pairs of approaches to the line of symmetry. These values are unique to the stimulus material, illumination levels, viewing angle, and experimental situation. Of much more interest are the trends which are present in the table. An analysis of variance produced $F$ ratios of 14.03 for the effect of lights (df $=2,22, \quad p>.01)$ and 34.69 for the up-down effect (df $=1,22, p>.01)$.

To assess the magnitude of the up-down effect, Table 3 was constructed by making a frequency distribution of the values of the 271 "same" terminal responses. Of the 17 responses which created half steps (called lighter rather than same when starting from dark end of range and vice versa) seven were $+1 / 2$ step, seven were $-1 / 2$ step, and the remaining three were greater than $-1 \frac{1}{2}$ steps. Table 3 shows the magnitude and direction of the up-down effect in the skew of the distribution of judgments.

In summary, our results show that the size of a difference limen for gray increases as we vary the illumination source from white, to red, to laser light and that it tends to be smaller when starting judgment trials from the darker rather than the lighter end of the stimulus range.

\section{Discussion}

We explain the observed up-down effect in terms of the black color of the stimulus mounting frame. In any series of judgments on a down trial, $S$ had an opportunity to observe the comparison chip depart from near the color of its surround by small increments to the same target-surround brightness contrast exhibited by the standard chip and the stimulus frame. On up trials, $S$ observed an initially high targetsurround contrast which decreased by small increments toward a lower contrast level. We feel this condition made judgments easier on down trials. The observed degradation in the brightness discrimination abilities of our Ss from white to red to laser light matches our predictions in regard to the effects of the spectral sensitivity of the eye and the masking effect of the standing diffraction pattern. The magnitude of the differences among difference limens reflects the magnitude of this effect under the experimental conditions.

\section{REFERENCES}

GRAHAM, C. (Ed.), Vision and visual perception. New York: Wiley \& Sons, Inc., 1965.

GUILFORD, J. P. Psychometric methods. New York: McGraw-Hill, 1955. OLIVER, B. Proc., IEEE (Correspondence), Vol. 51, p. 220, Jànuary, 1963.

RIGDEN, J. B., \& GORDON, E. L. Proc., IRE (Correspondence), Vol. 50, p. 2367, November, 1962.

NOTE

1. C. L. Askland is now at St. Cloud State College, St. Cloud, Minnesota.

(Continued from page 264)

Table 2

Latency Means (in seconds) for Each Group and Phase

\begin{tabular}{|c|c|c|c|c|c|c|c|}
\hline & \multicolumn{6}{|c|}{ Group } \\
\hline & & 1 & 2 & 3 & 4 & 5 & 6 \\
\hline Phase & 1 & $12.83(\mathrm{NP})$ & $12.74(\mathrm{NP})$ & $20.02(\mathrm{FL})$ & $21.97(\mathrm{SH})$ & $22.01(\mathrm{FL})$ & $21.52(\mathrm{SH})$ \\
\hline & 2 & $22.98(\mathrm{FL})$ & $25.23(\mathrm{SH})$ & 13.04(FL) & $13.18(\mathrm{SH})$ & $15.34(\mathrm{SH})$ & $15.01(\mathrm{FL})$ \\
\hline
\end{tabular}

\section{RESULTS}

Latency means (the time in seconds between slide onset and the first response) for each group and phase are presented in Table 2.

One latency mean was obtained for each $\mathrm{S}$ in each group for the first set of six problems (Phase 1). The group effect was significant $[F(5,54)=2.73, p<.05]$. By Neuman-Keuls comparisons NP groups each answered faster than any other group $(\mathrm{p}<.05)$.

One latency mean was obtained for each $\mathrm{S}$ in each group for the final set of six problems (Phase 2). The group effect was significant $[F(5,54)=6.15, p<.005]$. By Neuman-Keuls comparisons Group $1(\mathrm{FL})$ or $2(\mathrm{SH})$ took longer to answer than any other group $(\mathrm{p}<.05)$.

\section{DISCUSSION}

The finding that each NP group (Phase 1) answered faster than any other group agrees with the pilot study where it was determined that FL or SH was a punishing stimulus.

The finding that in Phase 2 Group 1(FL) took longer to answer than Group 3(FL), and Group 2(SH) took longer to answer than Group 4(SH) agrees with studies involving animal Ss (e.g., Azrin, 1960) and supported the first prediction that experience with a particular punishment renders individuals less sensitive to further presentations of this punishment.
The finding that in Phase 2, Group 1(FL) took longer to answer than Group 6(FL), and Group 2(SH) took longer to answer than Group 5(SH) also agrees with studies involving animal Ss (e.g., Terris \& Wechkin, 1967) and supported the second prediction that experience with a particular punishing stimulus renders individuals less sensitive to a novel punishment.

It would appear that human Ss respond to continued punishing stimulation as do some infrahuman organisms.

\section{REFERENCES}

AZRIN, N. H. Sequential effects of punishment. Science, 1960, 131, 605-606.

HAKE, D. F., \& AZRIN, N. H. An apparatus for delivering pain-shock to monkeys. Journal of the Experimental Analysis of Behavior, 1963, 6, 297-298.

HOLZ, W. C., \& AZRIN, N. H. Recovery during punishment by intense noise. Psychological Reports, 1962, 11, 655-657.

SKINNER, B. F. The behavior of organisms. New York: AppletonCentury-Crofts, 1938.

TERRIS, W., \& WECHKIN, S. Learning to resist the effects of punishment. Psychonomic Science, 1967, 7, 169-170. NOTES

1. Adapted from a Masters thesis submitted in partial fulfillment of the requirements for the degree of Master of Science.

2. Now a Ph.D. student at the Department of Psychology, Queen's University, Kingston, Ontario, Canada. 